\title{
Synthèse
}

\section{Le système de culture : un concept riche de sens pour penser le futur}

\author{
François Papy \\ Académie d'agriculture de France, \\ 92, avenue Victor Hugo, \\ 92170 Vanves \\ <papy.francois@numericable.fr>
}

\begin{abstract}
Résumé
Pour aborder les défis auxquels l'agriculture doit faire face (nourrir une population croissante en mobilisant moins de ressources naturelles non renouvelables et en limitant les dégâts environnementaux), le système de culture paraît être un concept pertinent pour les agronomes. Il est né avec l'agronomie à la fin du XVIII ${ }^{\mathrm{e}}$ siècle et au début du XIXe siècle. Il a ensuite été abandonné par les agronomes au cours d'une longue phase, de plus d'un siècle, où les recherches, centrées sur les processus de nutrition minérale et de protection des plantes, visaient, en lien avec l'amélioration variétale, l'obtention de rendements toujours plus élevés par une élimination, pas à pas, des facteurs limitants. Dans les pays industrialisés, une agriculture intensive, utilisant de plus en plus d'intrants, de façon de moins en moins efficace, s'est ainsi développée dont les limites écologiques et sociales apparaissent maintenant flagrantes. Réanimé dans les années 1970 du siècle dernier, le concept de système de culture est un outil utile pour concevoir et mettre en ouvre de nouvelles façons de cultiver. En renouant le fil rompu pendant plus d'un siècle, l'article fait ressortir la richesse des sens contenus dans le concept : mise en ouvre de théories sur les processus écologiques de la production végétale, il sert aussi à comprendre les pratiques des agriculteurs et à caractériser la nature des ressources naturelles utilisées ainsi que leur efficacité. Il permet d'aborder la question si actuelle de la durabilité des formes d'agricultures, qui revient de façon récurrente dans les préoccupations des agronomes.
\end{abstract}

Mots clés : agronomie ; histoire ; ressources naturelles ; système de culture.

Thèmes : agronomie; productions végétales.

\section{Abstract \\ The cropping system: A meaningful concept to think the future}

To take up the challenge that agriculture is facing (to feed an increasing population with less use of non-renewable natural resources) the cropping system seems a relevant concept for agronomists. It began with the birth of agronomy as a science at the end of the XVIIIth and the beginning of the XIXth centuries. Later, for more than a century, it was nearly unused by agronomists; Research was carried out on mineral nutrition and plant protection, aimed at producing higher and higher yields by eliminating limiting factors step by step. Thus, in industrialized countries, an intensive agriculture was promoted, using more and more inputs, with less and less effectiveness. Its social and ecological limits are now glaring apparent. Gradually used again since the last quarter of the XXth century, the concept of cropping system is useful to imagining and implementing new cultural methods. By reactivating the concept of cropping system, this paper shows it to be a meaningful tool for rethinking the future. It is used to conceive new cultural techniques from theoretical knowledge, to understand farmers' practices and to evaluate the ways of using natural resources. It thus fosters questions about sustainable forms of agriculture, which is a recurrent concern for agronomists.

Key words: agronomy; cropping systems; history; natural resources.

Subjects: agronomy; vegetal productions.

Tirés à part : F. Papy 
Je pense que l'histoire d'un domaine particulier est la meilleure manière d'assimiler ses concepts "

Ernst Mayer (1989)

agronomie est née comme discipline scientifique à la fin du $\mathrm{XVIII}^{\mathrm{e}}$ siècle avec l'émergence de connaissances sur la nutrition des plantes, les débuts de la méthode expérimentale (Stützel, 2007), la mise en débats des résultats de ces recherches (Boulaine et Gros, 1998) et, plus tard, l'institutionnalisation de la discipline (Denis, 2007). Dès la première phase de son existence, des tensions, souvent vives, se dessinent entre ceux qui conçoivent l'agronomie comme l'application de disciplines d'analyse des processus naturels et ceux qui en font une théorie de la mise en oeuvre concrète de techniques. La théorie minérale, largement vulgarisée par Liebig, à partir de 1840, marque le début d'une période où les tenants de la première conception dominent le champ de la discipline. Des agronomes comme Boussingault, Lawes, Gilbert, Schloesing, Müntz, Dehérain consacrent leur temps aux processus de fonctionnement du champ cultivé. Ils développent la chimie agricole dans la seconde moitié du $\mathrm{XIX}^{\mathrm{e}}$ siècle : puis, au tout début du $\mathrm{Xx}^{\mathrm{e}}$ siècle, grâce aux pédologues russes, la science du sol devient plus élaborée et traite également des comportements physiques et biologiques des sols (Demolon, 1931). La seconde moitié du $\mathrm{XIX}^{\mathrm{e}}$ siècle voit aussi apparaître une autre discipline : la pathologie végétale. Et, au milieu du siècle dernier, l'agronomie se présente comme une somme de disciplines spécialisées qui trouvent leurs applications dans une agriculture très productive, de plus en plus utilisatrice d'énergie et de produits chimiques de synthèse. Des conséquences sociales et écologiques graves apparaissent : disparition des agriculteurs les moins performants, d'une part, et, apparition de pollutions multiples et d'un gaspillage inconscient de ressources de plus en plus rares, d'autre part. Autant de raisons qui font réapparaître, à partir des années 1970 et 1980 du $\mathrm{xx}^{\mathrm{e}}$ siècle, une conception systémique de l'agronomie (Stützel, 2007).

À cette époque resurgit un concept central de l'agronomie, apparu à la naissance de cette dernière, disparu des esprits plus d'un siècle durant : le concept de système de culture (Sebillotte, 1990). En parcourant les usages faits de ce concept, nous allons voir qu'il englobe plusieurs sens : mise en œuvre de théories, outil d'analyse des pratiques agricoles, mode d'utilisation des ressources naturelles. Pour chacun d'entre eux, nous mettrons en parallèle les usages historiques du terme avec ses usages contemporains. À l'heure où, tout en préservant des ressources naturelles en quantité finie, il faut aider l'agriculture à trouver comment nourrir une population qui va croître au moins jusqu'en 2050, il nous a semblé utile de faire le point sur ce concept et de renouer ainsi le fil rompu par une conception très éclatée de l'agronomie.

\section{Cohérence entre théorie des processus et pratiques}

Au début du XVIII ${ }^{\mathrm{e}}$ siècle, l'anglais Jethro Tull propose une théorie de l'alimentation des plantes et en déduit des principes de culture. Marqué par la perspective atomiste et mécaniste de son époque, il interprète l'effet favorable, sur la croissance des plantes, du travail du sol qui divise la terre en agrégats: ce sont les "molécules de terre " qui sont absorbées. Aussi en déduit-il qu'il est inutile d'apporter des engrais et préconise-t-il de travailler le sol plusieurs fois avant semis et au cours du cycle cultural pour bien alimenter les plantes. Cette pratique le conduit à concevoir un ensemble cohérent de techniques. Utilisant un semoir mécanique (qu'il avait par ailleurs inventé pour économiser de la semence), il préconise des semis à grands écartements, surtout pour les espèces hautes et à long cycle de culture ou bien la division du terrain en bandes semées et bandes travaillées, alternées d'une année sur l'autre. Cette cohérence construite entre théorie et pratique est vite qualifiée de "système " dans le monde des agronomes après la vulgarisation qu'en fait Duhamel du Monceau (1750-1759) dans son traité de " nouvelle culture". Mais, expérimentateur averti, Duhamel du Monceau ne se contente pas de traduire; il évalue le système de Tull, modifie les explications que ce dernier donne de l'effet des techniques de semis à grand écartement, propose des modèles de charrue et surtout engage des collègues à faire eux-mêmes des expériences dont il publie les résultats dans les cinq tomes successifs du traité de la culture des terres. Par ces débats entre savants, l'agronomie est née (Boulaine et Gros, 1998).

Le terme de système de culture est définitivement consacré dans le cours complet de l'abbé Rozier (1783), qui se présente comme un dictionnaire universel. Lui donnant le sens de système cohérent entre théorie et pratique, Rozier distingue le système de culture de Tull de celui de Duhamel du Monceau, après avoir développé les théories de l'un et de l'autre et en avoir tiré les applications qui en découlent. Rozier expose ensuite ses propres idées : la terre proprement dite ne contribue pas à l'alimentation des plantes. Pour lui, la substance nourricière est l'humus qu'il dit être parfaitement soluble dans l'eau. Appliquant ces conceptions à la culture, il distingue labours et engrais. Les premiers divisent les molécules de la terre pour qu'elle serve "de matrice à la semence et de lien aux racines", de sorte qu'elles puissent " absorber les substances savonneuses". Les seconds, sous forme de fumier, " rendent à la terre les principes de fertilité, épuisés par les végétations précédentes". Si l'agriculteur n'a pas suffisamment de fumier pour ses terres de culture, il doit en produire sur place en introduisant dans la succession des prairies artificielles et "engrais verts"; au demeurant, la culture alternée d'espèces aux enracinements différenciés permet une meilleure exploration de la profondeur du sol. À partir de cette théorie de l'humus, qui sera encore défendue par Thaer, trente ans plus tard, Rozier propose aussi son système. Ces exemples, puisés à la naissance de l'agronomie, présentent le système de culture comme déduit de théories sur le fonctionnement du champ cultivé, même si, au début surtout, la théorie se déduit souvent d'une interprétation de l'effet des techniques (Sigaut, 1998).

Lorsque le concept de système de culture est remis à l'honneur, à la fin du Xx $x^{\mathrm{e}}$ siècle, d'abord timidement par Hénin (Hénin et al., 1969), puis, de façon décisive par Sebillotte (1974; 1990), c'est autour de cette même idée qu'il est conçu : c'est à partir de connaissances sur le fonctionnement de l'ensemble climatsol-plantes, dit ce dernier, que l'agronome doit concevoir des systèmes de culture. Chaque système de culture est "l'ensemble des modalités techniques mises en cuvre sur des parcelles traitées de façon identique "; il est défini par une 
succession de cultures, chaque culture (d'une espèce ou d'une association d'espèces) étant conçue comme "une combinaison logique et ordonnée de techniques qui permettent de contrôler le milieu pour en tirer une production donnée", que Sebillotte appelle "itinéraire technique".

À l'origine, comme aujourd'hui, les systèmes de culture sont donc des mises en œuvre pratiques de théories; aussi évoluent-ils avec elles. En opposition aux théories de Tull, pour qui la terre minérale est une source inépuisable de nutriments, s'est développée la théorie de l'humus, selon laquelle les plantes se nourrissent d'humus, produit lui-même par les plantes, qu'il faut apporter aux parcelles pour compenser les exportations. L'association de la culture à l'élevage, au sein du système que constitue l'entreprise agricole, permet " un transfert de fertilité " des pâtures aux cultures que Thaer (1811) quantifie. Ce dernier a tout à fait conscience que ce transfert ne suffit pas s'il n'y a pas d'apports extérieurs à l'entreprise agricole pour compenser les exportations. Là où la récupération de matières organiques venant des villes n'est pas possible, il faut, préconise-t-il, importer de l'azote en cultivant des légumineuses et réduire les pertes en implantant des espèces estivales sur les jachères (ce que nous appelons maintenant des cultures pièges à nitrates) et en récupérant le mieux possible les déjections animales en stabulation. Cependant, la théorie de l'humus ne contient pas l'idée d'une totale restitution au sol de ce qui lui est prélevé. Parce que les agronomes ne distinguent pas les éléments selon qu'ils sont puisés dans le sol ou dans l'atmosphère et qu'ils ignorent encore, au début du XIX ${ }^{\mathrm{e}}$ siècle, que l'essentiel de la masse produite est constitué de carbone, puisé dans l'air, d'oxygène et d'hydrogène venant de l'eau, ils pensent que les plantes donnent à la terre plus qu'elles n'en reçoivent. On peut, par une sorte de cercle vertueux, remonter la fertilité par l'introduction dans la succession des cultures d'" engrais verts " et de prairie artificielles, ce qui n'est vrai, on le sait maintenant, que pour l'azote et seulement dans la mesure des capacités fixatrices des micro-organismes du sol.

Plus tard et progressivement, le principe de restitution s'impose avec la théorie de la nutrition minérale des plantes. $\mathrm{Au}$ cours du $\mathrm{XIX}^{\mathrm{e}}$ siècle, à la suite des travaux de Saussure (1804), qui donnent une première vision synthétique de la nutrition carbonée, hydrique et minérale des végétaux, de ceux de Philipp Carl Sprengel, élève de Thaer, cette théorie minérale triomphe après la large médiation qu'en a faite Liebig (1841). Elle constitue progressivement le fondement de nouveaux systèmes de culture qui, appuyés par l'industrie chimique naissante, vont faire un usage croissant des engrais minéraux. L'association de l'élevage aux cultures ne semble plus indispensable à la conduite de ces dernières. Avec, au début du $\mathrm{Xx}^{\mathrm{e}}$ siècle, la synthèse de l'azote atmosphérique comme source d'engrais, et, plus tard, l'apparition des produits phytosanitaires minéraux puis de synthèse, avec aussi la motorisation, dans la seconde moitié de ce siècle, les systèmes de culture, dans les pays industrialisés, deviennent de plus en plus dépendants des énergies fossiles non renouvelables. La crise environnementale qui en découle va réorienter les recherches en agronomie.

\section{Cohérence entre théorie de gestion et pratiques}

Le souci de servir les agriculteurs éclairés est une préoccupation constante des agronomes de la fin du XVIII ${ }^{\mathrm{e}}$ siècle et du $\mathrm{XIX}^{\mathrm{e}}$ siècle. C'est pourquoi des parties entières de leurs traités sont consacrées à "l'entreprise agricole" (Thaer, 1811; de Gasparin, 1849). Les agronomes prennent en considération des questions comme l'organisation du travail dans l'entreprise. C'est ainsi que Duhamel du Monceau (1779) note que le premier labour de jachère, qui a pour but de détruire les mauvaises herbes, est souvent conditionné par la fin des autres travaux sur l'exploitation ou encore par le besoin des animaux en fourrage; de même, Mathieu de Dombasle souligne qu'une des raisons de la longévité du système de culture triennal avec jachère est de permettre d'étaler les travaux sur toute l'année (Morlon et Sigaut, 2008).

Ainsi les agronomes s'intéressent-ils à la mise en ouvre de leurs théories dans les entreprises agricoles: en retour, ils sont conduits à faire la théorie de cette mise en œuvre. Cette démarche apparaît clairement chez Schwerz (1889) $)^{1}$, pour qui le concept de système de culture permet de raisonner la gestion de l'entreprise. Cet auteur expose une démarche pour trouver des compromis entre l'intérêt à court terme de pratiquer les cultures les plus rentables et l'entretien des capacités productives du sol. S'il existe quelques modèles de successions culturales, le choix des successions à adopter pour chaque cas particulier reste délicat. Il propose d'identifier d'abord les espèces à cultiver en fonction du terrain et du climat, mais aussi des débouchés, de l'éloignement des champs, du travail disponible, des besoins internes de l'entreprise..., en veillant à avoir des espèces variées quant au niveau de leurs exportations ; il propose ensuite d'examiner les possibilités de faire se succéder les cultures en fonction du temps disponible entre récolte et semis (pour ameublir le sol et bien le nettoyer des adventices), des "principes nutritifs dont les plantes ont besoin " et de la capacité des plantes à se succéder elles-mêmes. Ces deux étapes franchies, il est possible de concevoir des " manières de diviser les champs et de faire se succéder les récoltes les unes aux autres" qui constituent autant de systèmes de culture. Cet auteur, qui préfère donner un mode de raisonnement plutôt que des normes, précise qu'il est possible de concevoir dans une entreprise agricole plusieurs systèmes de culture selon des caractéristiques du territoire à cultiver : nature des terrains, éloignement et modes de tenure des parcelles, etc.

Lorsqu'à la fin du $\mathrm{Xx}^{\mathrm{e}}$ siècle le concept de système de culture est repris par Sebillotte (1974) dans le sens premier que nous avons donné ; il est aussitôt utilisé pour comprendre les pratiques des agriculteurs comme étant des réponses à des problèmes techniques concrets dans les différentes situations d'action rencontrées (Papy et Lelièvre, 1979). À nouveau, l'entreprise agricole est vue comme un système (Osty, 1978).

Les systèmes de culture réapparaissent ainsi comme résultant, au sein de l'entreprise agricole, d'une gestion raisonnée des ressources productives (Aubry et al., 1998 ; Papy, 2001; Aubry et Michel-Dounias, 2006). Tirés, avec retard, du secteur industriel, les cadres théoriques de la représentation théorique des décisions dans

\footnotetext{
${ }^{1}$ La date est celle de la $7^{e}$ édition de la traduction du "Manuel de l'agriculteur commençant ", bien postérieure à la mort de son auteur, survenue en 1844
} 
l'exploitation agricole sont évidemment bien plus élaborés qu'un siècle auparavant. Ils diffèrent selon la nature des décisions. Les successions de cultures découlent d'une conception de la répartition des ressources productives entre les cultures, hiérarchisées selon leur intérêt économique, qui permet de définir des rotationscadres (Maxime et al., 1997). On parle de rotation-cadre pour exprimer qu'entre deux retours, sur une même parcelle, de la culture considérée comme principale pour son intérêt économique, s'intercalent d'autres cultures qui peuvent être interchangeables. Les itinéraires techniques résultent de la planification des actions dans laquelle sont introduites des règles de priorité entre activités et de pilotage en temps réel pour faire face aux aléas (Cerf et Sebillotte, 1988; Sebillotte et Soler, 1990 ; Pichot, 1996 ; Aubry et al., 1998). La modélisation des décisions qui génèrent les systèmes de culture est conçue avec la participation des agriculteurs, les agronomes cherchant désormais à comprendre les raisons de leurs pratiques et leurs objectifs (Collinson, 2000). Et des démarches d'innovation participative deviennent possibles par le couplage de modèles de décision à des modèles de processus biophysiques (Boiffin et al., 2001).

Ainsi, les agronomes manient le système de culture comme un concept charnière entre la connaissance de processus naturels et la mise en œuvre de règles de gestion de l'entreprise agricole et ils étudient aujourd'hui le champ cultivé "à la fois comme objet physique et comme objet d'application d'un raisonnement des techniques par un agriculteur" (Doré, 2006). Cette conception du champ cultivé sort l'agronomie du réductionnisme qui a si longtemps prévalu et qui consistait à pousser sans cesse plus avant l'analyse des processus biophysiques pour en déduire des applications, sans articuler ces dernières, ni étudier les conditions de leur mise en ouvre (Gibbon, 1994).

\section{"Le choix que fait}

\section{I'homme}

\section{des procédés d'exploitation}

\section{de la nature "}

Dans le tome V de son Cours d'agriculture, de Gasparin (1849) définit le système de culture comme "le choix que fait l'homme des procédés par lesquels il exploite la nature, soit en la laissant agir, soit en la dirigeant avec plus ou moins d'intensité en différents sens [...]; c'est l'ensemble des opérations agricoles qui constituent une exploitation ${ }^{2}$, et la nature des moyens physiques et mécaniques que nous mettons en usage, soit pour faire croître, soit pour récolter et utiliser des végétaux.. Cette définition lui permet de classer les différents systèmes de culture en fonction d'une artificialisation croissante, depuis le système forestier jusqu'aux systèmes qui emploient "des moyens physiques et chimiques autres que ceux de la nature".

Appliqué à une espèce cultivée, le concept d'itinéraire technique, défini par Sebillotte (1974), correspond bien à l'idée que se faisait de Gasparin du système de culture. Il désigne, en effet, le choix d'une combinaison d'usages et de niveaux de ressources naturelles en fonction d'objectifs visés, mais aussi celui d'un "itinéraire " parmi les différentes manières d'atteindre un même objectif. Cependant, de Gasparin fait du système de culture un absolu, pouvant s'appliquer à tout choix d'espèces et de successions culturales; au regard des choix d'usage des ressources naturelles, il tient pour négligeable la forte interdépendance, pourtant connue à son époque, entre ces choix et celui des espèces et de leurs modalités de culture. La formulation moderne du système de culture (Sebillotte, 1990), en revanche, en tient compte, qui associe le choix des espèces et de leur succession aux itinéraires techniques appliqués à chacune d'elles. Cependant, si l'on accepte de définir le concept à plusieurs niveaux d'échelle, la conception formulée par de Gasparin reste entièrement valable pour distinguer des grands types de systèmes de culture.

"Le choix que fait l'homme des procédés d'exploitation de la nature " est loin d'être toujours explicite. C'est à l'agronome de repérer, dans les pratiques agricoles, l'usage fait des ressources naturelles. De Gasparin rapproche ainsi l'agronomie de l'écologie. C'est clair dans le débat qu'il a avec Moll, futur professeur d'agri-

\footnotetext{
${ }^{2}$ |l faut entendre par exploitation mode d'utilisation des ressources naturelles et non ce que nous appelons couramment l'exploitation agricole que de Gasparin, comme tous les agronomes de son époque, qualifie d'entreprise agricole.
}

culture à l'Institut national agronomique de Paris. Au sein de l'entreprise agricole, le seul système considéré par Moll et qualifié par lui d'intensif ou d'extensif selon la quantité globale de ressources productives ramenée à la surface de Gasparin, à la suite de Thaer, en distingue plusieurs: le système de pâturage qui s'appauvrit en matières fertilisantes et le système de culture intensif qui bénéficie d'apports venant du premier, éventuellement d'achats. D'un système à l'autre, il y a transfert de matière; on peut aussi rajouter d'énergie, puisque la force de travail animal fournie aux cultures provient en partie des pâturages. Schwerz identifie, au sein de l'entreprise agricole, plusieurs systèmes de culture comme résultant d'une organisation raisonnée des ressources disponibles pour l'agriculteur ; de Gasparin le fait en y différenciant des portions du territoire traitées de façons identiques quant aux modalités d'utilisation des ressources naturelles, distinguant celles qui viennent de l'extérieur des autres. Le premier se tourne vers la gestion d'entreprise, le second vers l'écologie et, ce faisant, ouvre la voie aux questions actuelles de durabilité écologique des systèmes de culture.

On est cependant bien loin encore, en cette moitié du XIX ${ }^{\mathrm{e}}$ siècle, d'un rapprochement entre écologie et agronomie. L'écologie est en train d'émerger, mais les deux disciplines s'ignorent superbement (Chevassus-au-Louis, 2006). C'est que, dès l'origine, l'agronomie est orientée vers l'action: il faut commencer à agir avant de comprendre tous les processus, d'autant que les résultats de l'action permettent de mieux les comprendre. Tandis que, dès l'origine, l'écologie dédaigne l'action : seuls présentent de l'intérêt les écosystèmes naturels non perturbés par l'homme, considérés comme à l'équilibre. En France, particulièrement, la déconnexion des deux disciplines est très nette : l'agronomie dans les instituts de recherche et d'enseignement spécialisés, l'écologie dans les universités. Il faudra une double conversion pour rapprocher l'une de l'autre: i) que les écologues ne considèrent plus l'homo sapiens comme perturbateur, mais comme acteur central des systèmes écologiques (O'Neill, 2001) et s'impliquent dans leur transformation (Hubert, 2004); ii) que les agronomes prennent en compte la préservation et l'économie des ressources naturelles, mises à mal par un système économique qui fait se côtoyer, dans les milieux les plus favorables, des systèmes de culture 
toujours plus consommateurs d'énergie fossile et souvent polluants et, dans les plus pauvres, des systèmes extensifs, voire des friches.

Dès les années 1970, l'alerte est donnée sur la pollution nitrique de l'eau destinée à la consommation (Chrétien et al., 1974). Consacré à ce sujet, le rapport Hénin (1980) fait date. La sensibilisation aux autres pollutions se développe ensuite et, plus tard, la conscience de perte de biodiversité. Des agronomes se lancent alors dans la conception d'itinéraires techniques à faibles niveaux d'intrants (Meynard, 1985). Malgré les difficultés que cela représente, les indicateurs d'impacts environnementaux sur la qualité des sols, de l'eau, de l'air et sur la biodiversité sont maintenant pris en compte pour évaluer et concevoir des systèmes de culture (Loyce et Wery, 2006). En introduisant le concept de développement durable, le rapport Bruntland, publié en 1987 par la commission mondiale sur l'environnement et le développement, met l'accent sur la finitude de la planète et la raréfaction de certaines ressources : de l'énergie fossile sur toute la planète, de l'eau dans certaines régions. Aussi devient-il de plus en plus nécessaire d'évaluer la performance des systèmes de culture par des indicateurs d'efficience de l'eau et de l'énergie, introduite directement ou indirectement, notamment par la fertilisation azotée (Tilman et al., 2002).

Le sens que de Gasparin a donné au milieu du XIX ${ }^{\mathrm{e}}$ siècle au système de culture est d'une grande modernité. Mais pour inscrire l'agronomie dans une perspective de développement durable, il faut dépasser l'échelle des parcelles culturales et de l'entreprise agricole, domaine longtemps privilégié par les agronomes. Voyons comment.

\section{Apports \\ des géographes et de l'écologie des paysages}

Avant que, dans les années 1970 du siècle dernier, les agronomes n'aient redonné du sens au système de culture, les géographes ont commencé à utiliser le concept à partir de leur lecture des agronomes du siècle précédent. Faucher (1949) dans sa
"Géographie agraire" s'en explique : " $L a$ civilisation rurale s'est trouvée fondée non sur des cultures indépendantes les unes des autres, pratiquées à volonté, mais sur des associations de cultures, formant chacune un tout équilibré, adapté à sa fin propre, entraînant une répartition stricte des terres et des travaux. " Faisant référence à de Gasparin, Heuzé et, plus récemment, à Hitier, il trouve dans le concept de système agricole (qui inclut, pour lui, système de culture et système d'élevage) de quoi "expliquer les paysages ruraux et les genres de vie". À dire vrai, le concept de système de culture lui semble flou; ce n'est pas étonnant d'ailleurs, puisque de Gasparin le définit comme nous venons de le voir et que, pour Heuzé, le système de culture s'applique à l'ensemble de l'entreprise agricole. Du coup, l'usage du terme est un peu hésitant et va de système de culture à système de cultures ( $c f$. encadré 1). Ce que les géographes retiennent du terme, c'est la combinaison des techniques et des espèces cultivées qu'il signifie. Le système de culture relie une société locale (sa densité de population, son organisation économique, sa structure sociale) aux techniques de production agricole qu'elle met en œuvre sur son territoire (Papy, 1950).

Dans les excellentes thèses de géographie agraire qui ont fleuri au cours de la seconde moitié du $\mathrm{xx}^{\mathrm{e}}$ siècle, le concept de système de culture est peu employé ; on trouve pourtant dans ces travaux beaucoup d'éléments qui font comprendre comment les sociétés locales utilisent les ressources pour obtenir des produits agricoles. En 1974, date où les agronomes réaniment le concept, il figure encore dans le "Dictionnaire de la géographie" de George (1974) qui se réfère à Mathieu de Dombasle, mais il n'en est plus question dans "Les mots de la géographie" de Brunet et al. (1992). Nomadisant d'une discipline à l'autre, le concept n'a pas été partagé : dommage !

Retenons cependant des géographes que le système de culture peut être manipulé à l'échelle d'un territoire pour traduire comment l'homme fait usage des ressources naturelles afin d'en obtenir une production primaire de végétaux. Empruntant à ces derniers, à leur tour, le concept de paysage, dans une acception de " paysagisme utilitaire" (Sautter, 1991), des agronomes se sont interrogés : le paysage contient-il des indices de fonctionnement des systèmes de culture en tant qu'ils signifient la façon dont l'homme utilise les ressources naturelles pour la production agricole? (Collectif Inra-Enssaa, 1977 ; Deffontaines, 1996 ; Jouve, 2006). Pour aborder cette question, dans le but d'évaluer l'activité de production primaire de l'homme, l'agronomie ajoute aux études sur la production de paysage par l'activité agricole, des connaissances sur les processus écologiques mis en jeu par les systèmes de culture à l'échelle des territoires que lui apporte l'écologie du paysage (Burel et Baudry, 1999). Cette

\section{Encadré 1 \\ Système de culture ou système de cultures ?}

Les deux se disent, mais diffèrent par leur sens.

Un système de culture c'est une manière de cultiver, d'utiliser les ressources de la nature par une combinaison de techniques pour en tirer une production végétale. C'est le sens qu'utilisent la grande majorité des agronomes depuis le début de l'usage du terme ; ils écrivent culture au singulier, aux erreurs d'inattention près, qu'on rencontre parfois, même sous de bonnes plumes!

Un système de cultures est une combinaison de cultures comme, par exemple l'ensemble des cultures d'une exploitation agricole combinées entre elles du fait qu'elles relèvent toutes d'une même entité de gestion. Les géographes, les économistes emploient parfois cette expression.

Dans la littérature anglo-saxonne la terminologie n'est pas bien fixée. Dans Zandstra et al. (1981) cropping system désigne très clairement l'ensemble des activités de production végétale d'une exploitation agricole, alors qu'il n'a plus du tout ce sens chez les agronomes français à cette époque. On pourrait le traduire par système de cultures. Mais dans un ouvrage récent, Shrestha (2003) utilise le terme de cropping system dans un sens qui correspond assez bien à système de culture. Comptant sur une évolution sémantique de la terminologie anglo-saxonne, dans le titre de l'article, j'ai traduit système de culture par cropping system. 
discipline, qui a émergé dans les années 1980, étudie comment la configuration spatiale influe sur les processus écologiques; elle ne privilégie pas une échelle plutôt qu'une autre, mais étudie les possibilités de transposer les résultats de l'une à l'autre. Elle met en avant le rôle des structures linéaires, tâches, zones tampons et les conséquences de leur fragmentation et de leur connectivité sur les flux d'eau, de terre, de pollen (et donc de gènes), la dynamique des espèces végétales et animales. Aussi les éléments de structure comme bordures de champs, tailles et formes des parcelles, mares et fossés, bandes enherbées, habitats divers, très liés au demeurant au niveau d'intensification, doivent-ils être considérés comme éléments constitutifs du système de culture (Baudry et Papy, 2001). Ils ont un rôle de préservation des ressources, complémentaire de celui des parcelles de production; c'est l'ensemble des deux qui traduit la façon dont l'homme utilise les ressources naturelles pour produire. Stützel (2007) fait remarquer que tant que l'on était en situation de sous-fertilisation, il était important de faire des bilans de nutriments à la parcelle, comme les agronomes le font depuis Thaer ; mais, en situation de surfertilisation, dès lors qu'il y a des fuites hors des parcelles, c'est l'échelle du paysage qui devient pertinente.

C'est pourquoi, au sein du paysage, les zones d'égale apparence que sont les "unités agrophysionomiques" (Deffontaines, 1996 ; Deffontaines et Thinon, 2001), qui combinent à la fois indicateurs de milieu, d'occupation du sol et de configuration spatiale peuvent être considérées comme des entités où les pratiques agricoles présentent une certaine identité de préservation et d'économie des ressources naturelles. Même si elles ne renseignent que partiellement sur les systèmes de culture - des enquêtes sont souvent nécessaires, surtout dans les agricultures les plus artificialisées (Jouve, 2006) - elles n'en donnent pas moins une idée de leur organisation spatiale. Lorsque sont en jeu des processus biophysico-chimiques dans lesquels interagissent des structures spatiales, les agronomes étudient, pour les modéliser, la distribution de ces dernières et leurs fonctions respectives. C'est ainsi qu'ils peuvent concevoir de nouveaux systèmes de culture, inscrits dans le paysage, plus économes des ressources de la nature (Altieri, 1999; Colbach et al., 2001 ; Ludwig et al., 2004).

\section{Face aux défis de demain, repenser les systèmes
de culture
à l'échelle de la planète}

Depuis son origine, le concept de système de culture s'est enrichi des usages qui en ont été faits. Conçu au moment où émerge l'agronomie, à la fin du XVIII ${ }^{\mathrm{e}}$ siècle et au début du XIX ${ }^{\mathrm{e}}$ siècle, il sert à la fois à concevoir de nouvelles modalités de culture à partir de connaissances théoriques, à comprendre les pratiques des agriculteurs et à juger des façons d'utiliser les ressources naturelles. Pour tenir compte de la continuité spatiale des processus écologiques, les agronomes ont récemment élargi à l'ensemble d'un territoire cultivé son domaine d'application, longtemps cantonné à l'intérieur de l'entreprise agricole.

Par sa richesse, ce concept joue un rôle clé en agronomie; il permet de relire l'histoire de l'agriculture et de penser aux défis de demain. Avec des hauts et des bas, la durabilité des systèmes de culture a été un souci récurrent des agronomes (Robin, 2007). Nous l'avons déjà vu chez Thaer. Mais la théorie de l'humus, dont il disposait, ne permettait pas de comprendre qu'il ne pouvait y avoir restitution complète des éléments exportés vers les consommateurs urbains, sans un retour de la même quantité sur le territoire agricole. La théorie minérale a permis de faire des bilans minéraux et de les équilibrer à l'échelle de la parcelle. Des systèmes de culture de plus en plus consommateurs d'énergie fossile et d'éléments minéraux issus de mines se sont alors généralisés. Au fur et à mesure que progressaient la sélection des plantes et la maîtrise, par les pesticides, des populations végétales et animales antagonistes des espèces cultivées, les systèmes de culture intensifs (favorisés, aux États-Unis, dans l'Union européenne et au Japon, par des politiques de soutien qui diminuent le coût des ressources) n'ont cessé de se rapprocher du potentiel photosynthétique de production par hectare. Le souci de mettre un terme aux dégradations de ressources que ces systèmes entraînent et la conscience de la finitude des ressources fossiles imposent de concevoir de nouveaux systèmes, à bas niveaux d'intrants xénobiotiques, et de nouvelles modalités de recyclage des matières. Il est alors peu pensable de pouvoir atteindre les mêmes niveaux de potentiels photosynthétiques à l'unité de surface, même si l'on mobilise des processus écologiques améliorant l'efficience des intrants. Or le défi est là : alors que, sur les 6 milliards d'habitants de la planète, 854 millions sont sousalimentés, on attend de 8 à 9 milliards d'habitants en 2050. Comme les surfaces à conquérir pour la culture sont minimes, il faudra augmenter considérablement la production dans les régions dont les agricultures ont été jusqu'à présent laissées pour compte. Il est temps de concevoir et de mettre en ouvre de nouveaux systèmes de culture qui optimisent l'usage des ressources naturelles sur l'ensemble de la planète et non plus sur les quelques pays qui les accaparent.

\section{Remerciements}

Je remercie Thierry Doré, Pierre Morlon et Jean-Pascal Pichot pour leurs remarques sur la version initiale de ce texte.

\section{Références}

Altieri MA. The ecological role of biodiversity in agroecosystems. Agric Ecosyst Environ $1999 ; 74: 19-31$

Aubry C, Biarnès A, Maxime F, Papy F. Modélisation de l'organisation technique de la production dans l'exploitation agricole : la constitution de systèmes de culture. In : Brossier J Bent B, eds. Gestion des exploitations et des Bent $\mathrm{B}$, eds. Gestion des exploitations et des
ressources rurales - Farm and Rural Management. Etudes et recherches sur les systèmes agraires et le développement. Paris : Inra éditions, 1998.

Aubry C, Michel-Dounias I. Systèmes de culture et décisions techniques dans I'exploitation agricole. In : Doré T, Le Bail M, Martin P, Ney B, Roger-Estrade J, eds. L'agronomie aujourd'hui. Paris : Éditions Quae, 2006.

Baudry J, Papy F. The role of landscape heterogeneity in the sustainability of cropping systems. In : Nösberger J, Geiger HH, Struik PC, eds. Crop Science; Progress and Prospect. Wallingford : CABI Publishing, 2001.

Boiffin J, Malézieux E, Picard D. Cropping systems for the future. In : Nösberger J, Geiger $\mathrm{HH}$, Struik PC, eds. Crop Science; Progress and Prospect. Wallingford: CABI Publishing, 2001.

Boulaine J, Gros JP. D'Olivier de Serres à René Dumont, portraits d'agronomes. Paris : Lavoisier-TEC \& DOC, 1998.

Brunet $\mathrm{R}$, Ferras $\mathrm{R}$, Théry $\mathrm{H}$. Les mots de la géographie. Paris: La documentation française, 1992.

Burel F, Baudry J. Écologie du paysage. Concepts, méthodes et applications. Paris: TEC \& DOC, 1999. 
Cerf M, Sebillotte M. Le concept de modèle général et la prise de décision dans la conduite d'une culture. CR Acad Agric Fr 1988 ; 4 : 71-80.

Chevassus-au-Louis B. Refonder la recherche agronomique Les leçons inaugurales du groupe ESA. Angers : Groupe ESA, 2006.

Chrétien J, Concaret J, Mère C. Évolution des teneurs en nitrates dans les eaux d'alimentation (département de I'Yonne). Ann Agron $1974 ; 25: 499-513$.

Colbach N, Clermont-Dauphin C, Meynard JM. GeneSys : a model of the influence of cropping systems on gene escape from herbicide tolerant rapeseed crops to rape volun teers. II. Exchanges among volunteer and cropped populations in a small region. Agric Ecosyst Environ 2001 ; 83 : 255-70.

Collectif Inra-Enssaa. Pays, paysans, paysages dans les Vosges du sud. Paris: Inra éditions, 1977.

Collinson M. FSR ; Understanding farmers and their farming. In : Collinson $\mathrm{M}$, ed. $A$ His tory of farming system research. Wallingford : CABI Publishing, 2000.

Deffontaines JP. Du paysage comme moyen de connaissance de I'activité agricole à I'activité agricole comme moyen de production du paysage. Un point de vue d'agronome. CR Acad Agric Fr 1996 ; 4 : 57-69.

Deffontaines JP, Thinon P. Des entités spatiales significatives pour l'activité agricole et pour les enjeux environnementaux et paysagers. Courrier de l'environnement de I'Inra $2001 ; 44: 13-28$.

Demolon A. Principes d'agronomie. Tome 1. Dynamique du sol. 1 ère édition. Paris : Dunod 1931.

Denis G. L'agronomie au sens large. Une histoire de son champ, de ses définitions et des mots pour l'identifier. In : Robin P, Aeschlimann JP, Feller C, eds. Histoire et agronomie, entre rupture et durée. Paris: IRD éditions, 2007.

Doré T. Introduction générale. In : Doré T, Le Bail M, Martin P, Ney B, Roger-Estrade J, eds. L'agronomie aujourd'hui. Paris: éditions QUAE, 2006.

Duhamel du Monceau HL. Éléments d'agriculture. Paris : chez la veuve Desaint, 1779.

Duhamel du Monceau HL. Traité de la culture des terres, suivant les principes de M. Tull, Anglois. Paris : H. L. Guérin, 1750-1759.

Faucher D. Géographie agraire, types de cultures. Paris : librairie de Médicis, 1949.

Gasparin (de) A. Cours d'agriculture. Tome 5. Paris : La maison rustique, 1849.

George P. Dictionnaire de la géographie. Paris : Presses universitaires de France, 1974.
Gibbon D. Farming systems research/ Extension: Background concepts, experience and networking. In : Dent JB, MacGregor MJ eds. Rural and Farming Systems Analysis, European Perspectives. Wallingford: CABI Publishing, 1994.

Hénin S. Rapport du groupe de travail Activi tés agricoles et qualité des eaux, réalisé pour les ministères de l'Agriculture et de l'Environnement. Paris: ministère de l'Agriculture : ministère de l'Environnement, 1980 ; (rapport ronéoté).

Hénin S, Gras R, Monnier G. Le profil cultural. Paris : Masson, 1969.

Hubert B. Pour une écologie de l'action. Paris éditions Arguments, 2004.

Jouve P. La dimension spatiale des systèmes de culture: comparaison entre agriculture tempérée et agriculture tropicale. Cah Agric $2006 ; 3: 255-60$.

Liebig J. Chimie organique appliquée à la phy siologie végétale et à l'agriculture. Paris : For tin ; Masson, 1841.

Loyce C, Wery J. Les outils des agronomes pour l'évaluation et la conception de systèmes de culture. In : Doré T, Le Bail M, Martin P, Ney B, Roger-Estrade J, eds. L'agronomie aujourd'hui. Paris : éditions Quae, 2006.

Ludwig $B$, Le Bissonnais $Y$, Souchère $V$, Cer dan $\mathrm{O}$, Jetten $\mathrm{V}$. Intégration des pratiques agricole dans la modélisation du ruissellement et de l'érosion: les modèles LISEM et STREAM. In : Monestier $\mathrm{P}$, Lardon S, Seguin B, eds. Organisation spatiale des activités agricoles et processus environnementaux. Paris : Inra éditions, 2004.

Maxime F, Nicoletti JP, Leroy P, Papy F. Donne de la souplesse au choix d'assolement par des rotations-cadres. In: Aide à la décision et choix de stratégies dans les exploitations agricoles. Actes du colloque de Laon. Paris: Inra éditions : Le biopôle, 1997.

Mayer E. Histoire de la biologie: diversité, évolution et hérédité. Édition française. Paris Fayard, 1989.

Meynard JM. Construction d'itinéraires tech niques pour la culture du blé d'hiver. Thèse de docteur-ingénieur, Paris, Ina P-G, 1985.

Morlon P, Sigaut F. Pratiques des cultivateurs concepts de lettrés et enjeux sociaux : la troublante histoire de la jachère. Paris: éditions Quae ; Educagri, 2008.

O'Neill RV. Is it time to bury the ecosystem concept? (with full military honors, of course!). Ecology $2001 ; 121$ : 3275-84.

Osty PL. L'exploitation agricole, vue comme un système. Bull Techn Inf Min Agriculture $1978 ; 326: 43-9$.
Papy F. Interdépendance des systèmes de culture dans I'exploitation agricole. In : Malézieux E, Trébuil G, Jaeger M, eds. Modélisation des agro-écosystèmes et aide à la décision. Collection Repères. Paris: Montpellier : Editions Cirad-Inra, 2001.

Papy F, Lelièvre F. Les pratiques de céréaliculture dans une région aride de type méditerranéen : la plaine de Ben Guérir. Essai méthodologique. Rev Géogr Maroc 1979 ; 3 : 23-44.

Papy L. Os Sistema de cultura e suas modalidades. In: Boletim paulista de Geographia. $1950: 23-31$.

Pichot J. Diversité des systèmes de culture: un défi pour l'action. Cah Agric 1996 ; 5 : 445-9.

Robin P. Histoires et agronomies : problématique et concepts. Le point de vue d'un agronome. In : Robin P, Aeschlimann JP, Feller C eds. Histoire et agronomie, entre rupture et durée. Paris : IRD éditions, 2007.

Rozier JB. Cours complet d'agriculture. Tome 3. Paris : Libraires associés, 1783.

Saussure (de) NT. Recherches chimiques sur la végétation. Paris : chez la veuve Nyon, 1804. Sautter G. Paysagismes. In : Blanc-Pamard C, Lericollais A, eds. Agronomes et géographes. A travers champs. Bondy: Orstom éditions, 1991.

Schwerz JH. Manuel de l'agriculteur commencant. Villeroy C, Villeroy F, trad. Paris : Librairie agricole de la maison rustique, 1889

Sebillotte M. Agronomie et agriculture. Essai d'analyse des tâches de l'agronome. Cah Orstom (Sci Hum) 1974 ; 24 : 3-25.

Sebillotte M. Some concepts for analysing framing and cropping systems and for unders tanding their different effects. Proceedings of first congress of the European Society of Agronomy, Paris. 1990.

Sebillotte M, Soler LG. Les processus de décision des agriculteurs. I. Acquis et questions vives. In : Brossier J, et al., eds. Modélisation systémique et systèmes agraires. Paris: Inra éditions, 1990.

Shrestha A. Cropping systems, trends and advances. Binghampton (New York): Food Products Press, 2003.

Sigaut F. Entre pratiques raisonnées et science efficace : I'âge des doctrines en agronomie. In : Traditions agronomiques européennes. Paris : éditions CTHS, 1998.

Stützel H. Experimental agronomic sciences. Memories from yesterday, hopes for tomorrow. In : Robin P, Aeschlimann JP, Feller C, eds. Histoire et agronomie, entre rupture et durée. Paris : IRD éditions, 2007.

Thaer A. Principes raisonnés d'agriculture. Crud EVA, trad. Paris : Paschoud, 1811.

Tilman D, Cassman KG, Matson PA, Naylor R, Polasky S. Agricultural sustainability and intensive production practices. Nature 2002 $418: 671-7$.

Zandstra HG, Price EC, Litsinger JA, Morris RA. A methodology for on-farm cropping systems research. Manila (Philippines) : International Rice Research Institute (IRRI), 1981. 